\title{
ORIENTAÇÕES NACIONAIS PARA A REFORMA DO ENSINO MÉDIO: DOGMA E LITURGIA
}

\author{
MARIA SYLVIA SIMÕES BUENO \\ Faculdade de Filosofia e Ciências de Marília - Unesp
}

RESUMO

O estudo analisa criticamente os fundamentos das atuais diretrizes nacionais para o ensino médio brasileiro, dando especial enfoque à sua coerência com tendências mundiais e seus nexos com recomendações de agências internacionais para reformas educativas nos países emergentes. Discute, outrossim, as vicissitudes e peculiaridades do processo de formulação das referidas diretrizes e sugere o aprofundamento da discussão, indicando aspectos polêmicos que merecem maior reflexão.

ENSINO MÉDIO - POLITICAS EDUCACIONAIS - DIRETRIZES CURRICULARES NACIONAIS

\section{ABSTRACT}

THENATIONAL DIRECTIONSPROPOSAL FORSECONDARY SCHOOL:DOGMAAND LITURGY. This paperdeals with framework underlying the current national directions for Brasilian secondary school, with special emphasis to its harmony with global trends and its bonds to international agencies advices concerning educational reforms in the emergent contries. On the other hand, it discusses vicissitudes and peculiarities of its formulating process; it also points out controversial aspects that should deserve more careful study, therefore it puts forward a farreaching discussion on the subject.

Este artigo está vinculado originalmente à pesquisa: O salto na escuridão: pressupostos e desdobramentos das políticas atuais para o ensino médio, tese de doutorado defendida junto ao Programa de Pós-Graduação da UNESP, no Campus de Marília, em I5/3/99. O artigo foi apresentado como trabalho no GT Estado e Política Educacional, por ocasião da $22^{\mathrm{a}}$ Reunião Anual da ANPEd (1999), com apoio financeiro da FUNDUNESP. 


\section{UM PALCO MAL ILUMINADO}

discurso governamental brasileiro deste final de século propala a instalação de um processo transformador fundado e construído no seio de um consenso nacional quanto à importância e aos rumos da educação. Nessa perspectiva, o ideário educacional consubstanciado nos documentos oficiais estaria dotado, segundo seus defensores, de unidade e universalidade invejáveis que dispensam a análise crítica e, portanto, reparos de quaisquer natureza. $\bigcirc$ que fundamenta essa certeza? Até que ponto o raciocínio unívoco impregna o cenário educacional e legitima políticas e ações governamentais?

$\mathrm{Na}$ verdade, tal consensualidade traduz o horizonte desenhado pelo movimento continental de concertación educativa preconizado para os países emergentes'. Essa perspectiva orienta redefinições progressivamente aperfeiçoadas no cenário educacional, em direção a um "pan-paradigma", enquanto resistências e contraposições são desmobilizadas. Em contrapartida, o adesismo e a inércia contagiam focos de resistência. Assim, a diretividade - e não o consenso - parece constituir o traço forte das transformações em andamento.

O ensino médio e a educação profissional são atingidos de modo peculiar e contraditório por essa espécie de pentecostes conceitual. Os passos da reforma nesse âmbito declaram inspirar-se em tendências orientadoras de transformações educativas efetivadas ou em andamento no Norte Econômico, com vistas a uma inserção mais satisfatória do País na sociedade global da tecnologia e do conhecimento. Sem dúvida, tal referência implica profundas alterações no sistema educacional e isso requer recursos, em especial de ordem financeira. Que providências têm sido encaminhadas nesse sentido?

Para início de conversa, o eixo economicista, que sustenta essas falas, concentra esforços na escola fundamental, recomenda políticas de recuperação (redução?) de custos no ensino médio, profissional e superior, estimula a informalidade sem pré-requisitos em programas de qualificação, canaliza a maior fatia de responsabilidades para a iniciativa privada, o setor empresarial e a comunidade e cria um vazio incômodo no que se refere a recursos públicos para os níveis e modalidades de ensino "não obrigatórios".

A imposição de "escolhas de Sofia" a estados federados compromissados com outros níveis e modalidades de ensino, associada a balizas refratárias passíveis de interferências de ordem social, política e acadêmica, reduz possíveis confrontos a jogos de luzes numa encenação em que tudo está "pesado, contado e dividido". Esse é o pano de fundo de perspectivas pouco nítidas e encaminhamentos duvidosos para o ensino médio. Há o perigo de preservação, em nova perspectiva, da trama de indefinições e dubiedades já tradicional no setor.

I. Os países emergentes reiteraram, em 1993, o compromisso de atender as necessidades básicas de aprendizagem e convocam "as instituições financeiras internacionais para que, sob o prisma de ajustes estruturais, reconheçam a educação como investimento crítico..."(Declaração de Nova Delhi, 16 dez. 1993). 
Meandros retóricos ocultam o paradoxo existente entre as promessas de políticas de extensão, qualidade e modernização para esse nível de ensino e a idéia de racionalização de recursos segundo prioridades excludentes. Está em jogo, nesse caso, a questão da responsabilidade pela oferta e manutenção desse ensino, não sua importância e necessidade. O Estado provedor sai de cena. Entra em cena o Estado gerador, incentivador e avaliador de políticas educativas. A concretização dessas promessas é a grande interrogação.

Duas faces ideológicas são exploradas nesse processo: de um lado, o véu do consenso oculta a realidade pela mesma ótica que a revela e pretende converter pessoas à "causa" pela internalização de princípios e pressupostos "universais e indiscutíveis"; de outro, a falta de conhecimento e controle do público sobre o curso da ação facilita o uso da máscara ideológica, isto é, do disfarce, da mistificação, da manipulação (Merquior, 1997).

A exposição dos referidos mecanismos é necessária para o desvelamento e a discussão dos fundamentos das reformas educativas. Ao desarmar armadilhas, abrir cortinas e desmontar encenações, será talvez viável romper com decisões apressadas e imposição de simulacros e abordar, de forma mais objetiva, a realidade vivida e os caminhos possíveis.

\section{AS IDÉIAS-FORÇA: OBJETOS DE DEVOÇÃO}

É importante assinalar, de plano, com relação às idéias-chave orientadoras das reformas do ensino médio brasileiro, que o problema está menos no seguimento de tendências mundiais e mais no seu dimensionamento em nível nacional. É neste âmbito que paradoxos conceituais - presentes mas não explicitados ou discutidos no delineamento de diretrizes - podem gerar perplexidades infrutíferas, em lugar de alicerçar transformações construtivas.

É o caso da suprema responsabilidade pelas transformações sociais delegada à educação, ao mesmo tempo em que ela é reduzida a fator que contribui para associar crescimento econômico, qualidade de vida e democratização; do conhecimento humano rebaixado a recurso estratégico do desenvolvimento, confundido com informação e, nessa dimensão, considerado como base da cidadania política; da concepção redutora de trabaIho, visto como mero fator de produção e não como categoria ontológica e econômica fundamental; da visão messiânica da tecnologia plantada em contexto no qual a relação linear entre desenvolvimento humano e mercado potencial constitui um paradoxo e qualquer mudança no processo do trabalho jamais abrangerá a todos os trabalhadores; de uma concepção de necessidades humanas que tem por referência a finitude da economia e não o homem em sua plenitude; do raciocínio economicista/empresarial subjacente aos modelos educativos e aos modelos de financiamento que associa um rumo retórico vinculado à qualidade para ações centradas no quantitativo; de um conceito de qualidade vinculado à perspectiva empresarial de eficiência, eficácia e política de resultados e identificada com 
aperfeiçoamento de capital humano pela otimização dos meios; da visão difusa de educação tecnológica associada a uma divisão inexorável entre escolas de formação geral e ensino profissionalizante.

É possível observar que, uma vez aposto o véu e afivelada a máscara, o passo seguinte no delineamento de políticas para o ensino médio é a assunção de diretrizes "impenetráveis", isto é, que não perdem tempo com maiores esclarecimentos. Repetindo o que Humpty Dumpty disse a Alice no país dos espelhos, "por impenetrabilidade eu quero dizer que já debatemos muito esse assunto e que seria justo que você dissesse o que fazer agora, pois não podemos ficar nesse ponto toda a vida" (Carroll, | 96।, p. 81).

Assim, o que é classificado como obviedade dispensa justificativas e debates mesmo que não haja clareza e concordância geral sobre o que é cristalino e inquestionável. A argumentação oficial resvala para o dogmatismo que contrapõe a fé (adesão) à heresia (divergência), e os princípios de participação e autonomia transfiguram-se em fetiches do poder desenvolvidos nos limites do permitido, do previsto e do estabelecido.

Pretensas obviedades no ensino médio e profissional incluem, dentre outras coisas: a necessidade indiscutível de fragmentação da estrutura educacional, a opção exclusiva por modelos de educação geral, a não-eqüidade, a distorção e o desperdício associados ao ensino técnico e a exigência de referenciais econométricos para a definição de políticas nessa área.

Os ícones da "nova ordem", em particular competitividade e revolução tecnológica, impregnam o discurso legal e orientam a formação geral por uma visão restrita e pragmática do trabalho humano, dimensionado como ocupação. Os artigos 35 e 36 da Lei de Diretrizes e Bases da Educação Nacional - LDB - registram, nesse sentido, as seguintes expressões: "ser capaz de se adaptar com flexibilidade a novas condições de ocupação"... "domínio dos princípios científicos e tecnológicos que presidem a produção moderna". Essa concepção também está presente nos objetivos da educação básica, elencados no artigo 22.

Nesse caso, é ingênuo acusar a LDB "minimalista" de sincrética e invertebrada. Imbricada a documentos que a precedem e sucedem, a Lei consubstancia a espinha dorsal flexível - mas categórica - de um modelo educacional no qual ensino médio e educação profissional assumem funções paralelas definidas e isso é posto como questão resolvida.

○ significado das diretrizes da educação nacional é discutido por Guiomar Namo de Mello (Brasil, 1998a, p. 5-8) com base em Horta (1989) e Ferreira (s.d.). A conselheira do Conselho Nacional de Educação - CNE -, relatora do Parecer n. 15/98 (ver Brasil, 1998a) da Câmara de Educação Básica - CEB -, aponta a distinção entre os preceitos genéricos e fundamentais da LDB, inspirados no princípio da descentralização, e as indicações e instruções para a ação oriundas de órgãos técnicos e colegiados.

No primeiro caso, por mais flexível que seja a LDB, suas disposições são imperativas e duradouras. "Sua revisão, ainda que possível, exige a convocação de toda sociedade 
representada no Congresso Nacional" (Brasil, 1998b, p.6). Já as diretrizes de ação, mesmo obrigatórias após aprovação e homologação, subordinam-se "à vontade das partes envolvidas no acordo que representam"(idem, p.8) e, assim, "requerem revisão mais freqüente" (idem, p. 6). Na prática, as coisas não parecem tão claras e distintas.

Se a LDB é responsável pelo estabelecimento de linhas reguladoras mais perenes para a educação brasileira, no caso do ensino médio e da educação profissional essas direções já estavam esboçadas - sem consulta prévia ao destinatário - na Proposta de Governo (Cardoso, 1994) e nos textos oficiais desde o Planejamento Político-Estratégico do MEC (Brasil, 1995).

Os eixos de discussão (qualidade e quantidade) e de orientação (flexibilização e avaliação) espelham-se em tendências exógenas e suas diretrizes básicas, antes de registradas na Lei - que deveria expressar a vontade da nação convocada -, e transparecem em mudanças subjacentes à ação da administração educacional. Tendências, coincidências e consensualidades à parte, definições e detalhes ultrapassam relações lógicas de espaço e tempo, antecipam reduções à flexibilidade da Lei e põem dúvidas quanto ao pacto democrático de sua construção.

É evidente que uma administração concentrada em amplas reformas educativas não poderia ficar amarrada a um arcabouço legal retrógrado e equivocado enquanto a discussão da nova LDB não chegasse a termo. Porém, causa espécie que, embora o ensino médio não fosse assolado "por uma saraivada de antecipações legais", da qual a educação profissional e os outros níveis de ensino não escaparam (Cunha, 1997, p. 2), as ações ministeriais caminhassem tranqüilas pelas trilhas desenhadas no Plano Político-Estratégico do MEC, na certeza da aprovação de uma lei que as legitimasse.

O ideário subjacente a tais ações é coerente a diagnósticos e recomendações de agências externas para o setor ${ }^{2}$ e defendido por especialistas brasileiros que circulam por organismos internacionais, como Castro, Mello e Oliveira ${ }^{3}$. A confluência de forças, concepções e interesses concorre para que as perspectivas de análise e a definição de rumos para o ensino médio sigam a senda consensual percorrida por outros países latino-americanos.

2. As diretrizes para o ensino médio e a educação profissional nos países em desenvolvimento são confirmadas no documento Prioridades y Estrategias para la Educación, publicado em 1996 (ver Banco Mundial), com edição original em inglês de 1995. Também de 1995 é o trabalho de Crouch, enquanto consultor do Banco Mundial. $O$ autor vislumbra perspectivas difíceis para a expansão do ensino médio na América Latina e coloca como opções viáveis para maximizar a relação custo-efetividade a descentralização e a privatização. Justifica essas alternativas pela evidência da eficácia maior da iniciativa privada, pela ineficiência interna dos sistemas educativos e pela necessidade de redefinir o papel do Estado na distribuição de bens.

3. Os textos de Cláudio Moura e Castro (1997) e de João Batista Oliveira (1995) seguem a referida orientação e foram largamente divulgados pelo MEC. O documento que Castro elaborou em parceria com Carnoy, para a reunião anual do BID// 996, sintetiza o ponto de vista das instituições financeiras (Castro e Carnoy, 1997, p. 5680). A conselheira Guiomar Namo de Mello defende posições semelhantes desde o início da década. Em I993, no livro Cidadania e Competitividade, ressalta as exigências contemporâneas e futuras de novas formas de exercício da cidadania em sociedades plurais e saturadas de informação. Isso exige, na sua opinião, a formação de habilidades cognitivas (dentre elas sobressai o domínio da língua) e competências sociais (conhecimento, informação e visão 
Nessa perspectiva, as diretrizes discursivas para esse nível de ensino apontam para a expansão do atendimento e a melhoria da qualidade. Os problemas existentes, em especial os relativos à estrutura, financiamento, expansão e descaminhos do ensino técnico, sustentam a proposta de: currículos flexíveis, centrados na redefinição de objetivos e conteúdos e na superação da rigidez do ensino técnico; acesso com qualidade pela "criação de mecanismos alternativos para expansão do atendimento à demanda, com base em novas fontes de financiamento e formas de gestão", envolvendo parcerias e redefinição de funções; estratégias alternativas de oferta, como ensino a distância (Brasil, 1995, p. 19 e 22).

O MEC (Brasil, 1995, p. 22) propõe, para a rede federal de ensino técnico, "separar do ponto de vista conceitual e operacional a parte profissionalizante da parte acadêmica", articular escola e empresa e flexibilizar o ensino em razão do mercado. Encaminha, ainda, a avaliação do ensino médio nos moldes do que será posteriormente aprovado na LDB. Portanto, além de inspirar-se em diagnósticos e recomendações internacionais, o Plano Político-Estratégico assume um caráter antecipatório em relação à legislação educacional.

As disposições para o ensino médio na nova LDB compõem, assim, o referendo de um programa do MEC em andamento, preparado com assistência direta especializada do $\mathrm{BID}^{4}$ e seguindo um plano de ação com datas adrede acordadas. Um cronograma que segue tranqüilo após a aprovação da Lei e permite que, já no início de 1997, o Programa de Reforma da Educação Profissional - PROEP -, resultante do acordo financeiro MEC/BID BR-0247, inclua oficialmente as novas diretrizes legais e antecipe, tanto os termos do futuro decreto da reforma da educação profissional, como as medidas complementares do MEC 5 .

O PROEP assinala que, em decorrência da Emenda n. $14 / 96$, "a maioria dos estados contará com recursos liberados que poderão ser dedicados à expansão do ensino médio" (Brasil, s.d.). Registra ainda que "adicionalmente, o projeto tem por objeto impulsionar a reforma da educação média através do financiamento de estudos preparatórios, assim como celebrando acordos com cada estado participante do Projeto, no que se refere ao seu avanço nesta área"6 (idem).

Nesse panorama, diretrizes amplas, diretrizes de ação, acordos financeiros, planos

mais ampla dos valores). No texto A reforma do ensino primário e secundário na Inglaterra( I994, p.47), assinala que o grande desafio na produção de resultados de aprendizagem que garantam o atingimento de tais objetivos é a gestão adequada dos recursos materiais e humanos disponíveis.

4. Além da assessoria do BID, o MEC contou com o apoio técnico da Oklahoma State University para a definição de parâmetros curriculares, via convênio e consultores contratados pela UNESCO.

5. É importante registrar que constituem referências expressas do Projeto BR-0247 (PROEP) as seguintes publicações: Opportunity Foregone: Education in Brazil, editado por Nancy Birdsall e Richard Sabot (BID, 1996), Pobreza, Desigualdad y Formación de Capital Humano en América Latina de Juan Luis Londoño ( 1996), Relatório Sobre o Desenvolvimento Humano no Brasil- 1996 (Brasil, 1999) e O Secundário: Esquecido em um Desvão do Ensino?, de Cláudio de Moura Castro (1997)

6. O objetivo " $m$ " constante desse Informe é o seguinte: "impulsionar a reforma e expansão do ensino geral de nível médio para que se concentre em uma melhor e mais relevante educação acadêmica." 
e propostas, bem como ações propriamente ditas, intercalam-se, mesclam-se e atropelam-se, o que torna difícil sua separação e qualificação.

Com relação às diretrizes de ação, vale a pena destacar as relativas à organização curricular do ensino médio, objeto do Parecer CNE/CEB n. I5/98 e da Resolução CNE/ CEB n.3, de 26/06/98. Esses dispositivos norteadores partem das "propostas da base curricular nacional e de organização do ensino médio”, elaboradas na SEMTEC-MEC (Brasil, 1997a) com a colaboração de especialistas internacionais ${ }^{7}$ e nacionais e encaminhadas ao CNE para apreciação e deliberação.

O documento original do MEC sem dúvida significou, no âmbito do CNE, mais um estimulador de debates do que uma proposta de regulamentação, uma vez que não aprofunda a discussão de suas proposições. Nesses termos, a expectativa de que as diretrizes em pauta fossem aprovadas para vigorar em 1998 não se concretizou. Na verdade, os conselheiros não se limitaram a aprimorar a redação; foram muito além disso. Em sucessivas versões do documento, o CNE realizou correções, ampliações e aperfeiçoamentos progressivos, procurando preencher lacunas, dirimir dúvidas conceituais e indicar claramente posições teóricas e caminhos escolhidos para o ensino médio.

Esse esforço teórico resultou num tratado acadêmico de 70 páginas, uma espécie de "livro branco" do ensino médio brasileiro, que reforça balizas internacionais para a educação nos países emergentes. Como exemplo, o subtítulo "Ensino Médio no Brasil: segmentação e exclusão a serem superadas" foi alterado, no texto final, para "Educação pós-obrigatória no Brasil: exclusão a ser superada". Há, ainda, restrições veladas à gratuidade do ensino e saneamentos ideológicos: à fl. 35, a expressão "mais favorecidos" foi trocada por "entre os que podem custear uma carreira educacional mais longa".

As Diretrizes Curriculares Nacionais para o Ensino Médio - DCNEM consubstanciam um conjunto de definições doutrinárias sobre princípios, fundamentos e procedimentos a serem observados na organização pedagógica e curricular de cada unidade escolar integrante dos diversos sistemas de ensino (Brasil, 1998). Como tal, não têm a mesma permanência da Lei por constituírem "indicações para um acordo de ações", mas são as determinantes legais da ação pedagógica.

Em princípio, a obrigatoriedade desses norteadores será confirmada pela sua eficácia na orientação do cotidiano escolar e a própria natureza da doutrina pedagógica pressupõe questionamentos e revisões permanentes (Brasil, 1998). A impenetrabilidade das diretrizes é, então, passível de superação?

Na prática, questionamentos e revisões podem ser comprometidos em alguns pontos básicos. É dominante o caráter dogmático de fundamentos e princípios; a reverência às

7. Além das consultorias identificadas no Projeto BR-0247, existe um intercâmbio de cooperação técnica e científica Brasil/Espanha mantido desde 1989 e renovado para o período 1995-98. Em seus termos, o apoio à implantação da reforma curricular do ensino médio constitui uma área de especial interesse da SEMTEC. 
idéias-força e a sacralidade do consenso reduzem e delimitam a matéria de discussão. Todavia, há pontos controversos e obscuros que merecem uma reflexão mais detida, sob pena de o "livro branco do ensino médio" transmudar-se em livro em branco nas tentativas de concretização de suas proposições no cotidiano da escola.

Em primeiro lugar, o discurso oficial executa um movimento pendular entre a necessidade de assumir compromissos mais consistentes com o ensino médio e a perspectiva de manter uma política de enxugamento e redistribuição financeira na área educacional.

O objetivo de universalização do ensino médio está atrelado à aceitação do anúncio de uma "política problemática" da expansão referenciado na racionalização de custos. Tal política envolve a busca de fontes alternativas de recursos, a articulação de compromissos que liberem o poder público da assunção de grandes responsabilidades e um planejamento rigoroso que reduza o intransferível a um mínimo de baixo custo parcelado a longo prazo.

Nesse prisma, as proposições de diversidade orientam-se para a maior responsabilização do aluno por sua trajetória educacional, pautada em diferenças individuais e buscada no balcão de múltiplas ofertas do sistema e do mercado. A flexibilização, justificada pelas transformações aceleradas da virada do milênio, aponta para a adoção de alternativas mais baratas representadas pelas novas tecnologias educacionais. Não estaria, nesse caso, sendo recriada a antiga "escola elétrica", travestida de um modernoso paramento eletrônico virtual?

Em segundo lugar, o fato de a prolongada discussão acadêmica sobre a dualidade da escola média brasileira, suas motivações e raízes históricas, ser atalhada por uma brusca separação entre ensino médio e educação profissional é, no mínimo, surpreendente.

Todavia, na letra do Parecer CNE/CEB n. I5/98, o nó górdio do ensino médio foi desatado e a questão está resolvida. As diretrizes pretendem exprimir a integração plena entre os ideais humanistas mais amplos e os objetivos econômicos mais pragmáticos relativos ao mundo do trabalho. Por "opção doutrinária", a preparação geral para o trabalho e a formação geral do educando não são dissociadas na Lei e, nesses termos, todos os conteúdos curriculares devem ter por referência o contexto do trabalho ${ }^{8}$. É textual que "essa preparação geral para o trabalho abarca portanto os conteúdos e competências de caráter geral para a inserção no mundo do trabalho e aqueles que são relevantes ou indispensáveis para cursar uma habilitação profissional e exercer uma profissão técnica" (Brasil, 1998a, p. 53).

Dentre os conteúdos e competências de caráter geral estariam noções mais amplas sobre o papel e o valor do trabalho, os produtos do trabalho e as condições de produção.

8. Embora o Parecer CEB/CNE n. I 5/98 pareça, em alguns momentos, inclinar-se por uma concepção mais abrangente de trabalho, como categoria ontológica e econômica fundamental, fica evidente, às fls. 44 e 45 do citado instrumento legal, que sua visão está restrita aos termos dos artigos 35 e 36 da LDB. 
No segundo caso, estariam os conteúdos vinculados mais ou menos especificamente ao preparo profissional formal ou em ambientes de trabalho (idem, p. 53-4). A composição flexível dos currículos escolares, fundada nessa articulação, seria fruto do exercício da autonomia inovadora das escolas. Essa construção criativa teria como eixos organizadores o trabalho e a cidadania em suas manifestações contextualizadas e, como referência necessária, a diversidade das trajetórias de vida dos alunos?.

A matriz inspiradora assumida dessas novas proposições é o movimento reformista para o ensino médio, em andamento no mundo desenvolvido, "fortemente referenciado nas mudanças econômicas e tecnológicas" deste final de século. Tal movimento consubstancia, após uma primeira etapa de integração e desespecialização, orientadas pelo mundo do trabalho, redefinições mais radicais que resgatam o humanismo e convergem para a constituição de "uma cidadania de qualidade nova" (Brasil, 1998a, p. 17-20).

A superação da dualidade repousa, nesse cenário otimista, na concepção de formação geral básica do trabalhador exigida por novos padrões tecnológicos e de organização social do trabalho. Esse conceito recupera o tema das competências e sua relação com os currículos escolares, deixando em segundo plano a idéia de qualificação que sustenta antigos padrões.

Ferretti (1997, p. 227) alerta, porém, para distorções e simplismos que parecem impregnar o pensamento atual, expressos em nexos lineares e causais entre temas complexos como inovação tecnológica, reestruturação do trabalho e novas exigências educacionais.

Nessa perspectiva, a mística da passagem do milênio pode levar a generalizações ingênuas sobre a estrutura produtiva, como, por exemplo, a percepção da revolução tecnológica como algo já consumado e caracterizado por padrões estáveis que permitem a projeção de horizontes definidos para o trabalho, o mercado, a sociedade e a escola. Nesses termos, minimizadas a complexidade e a ambigüidade dos múltiplos contextos em mutação, são geradas respostas genéricas, prontas e acabadas em relação ao perfil do jovem trabalhador e das "competências" que precisa desenvolver e demonstrar.

Em tal quadro, os momentos e espaços de debate sobre ensino médio e educação profissional, e suas possibilidades de articulação/desarticulação, não parecem ter sido eficientes e suficientes para superar incoerências, divergências e contradições no campo conceitual e oferecer às escolas um referencial de decisão abrangente, objetivo e seguro.

9. É flagrante a dubiedade da concepção de flexibilidade à vista do fatalismo conformista inerente às trajetórias dos "destinados ao trabalho" e a responsabilidade individual em arcar com esse destino, expressado no texto do Parecer CEB/CNE n. I 5/98: "A duplicidade da demanda continuará existindo porque a idade de conclusão do ensino fundamental coincide com a definição de um projeto de vida, fortemente determinado pelas condições econômicas da família e, em menor grau, pelas características pessoais. Entre os que podem custear uma carreira educacional mais longa esse projeto abrigará um percurso que posterga o desafio da sobrevivência material para depois do curso superior. Entre aqueles que precisam arcar com sua subsistência precocemente ele demandará a inserção no mercado de trabalho logo após a conclusão do ensino obrigatório, durante o ensino médio ou imediatamente depois deste último" (Brasil, 1998a, p.35). 
O Parecer CNE/CEB n. 15/98 reporta-se às várias dimensões das habilidades e competências no ensino médio, dando destaque àquelas de caráter geral (cognitivas e sociais), "dentre as quais a capacidade de aprender é decisiva"10 (Brasil, 1998a, p. 36). Deixa para as escolas, porém, a missão quase impossível de identificar "conhecimentos, competências e habilidades de formação geral e de preparação para o trabalho" (idem, p. 55) que poderão ser objeto de aproveitamento de estudos em habilitações profissionais específicas (tarefa da escola média), e de avaliar se já foram adquiridos no ensino médio, atestando o caráter profissionalizante das disciplinas e dos estudos que lhes deram suporte (tarefa de escolas e programas de formação profissional).

Essa responsabilidade, além de exigir de equipes escolares imaginárias o conhecimento profundo dos fundamentos científicos e tecnológicos do processo produtivo e dos meandros mais sutis do mercado e da vida em sociedade, aliado a uma inusitada capacidade de prever o imprevisível, pressupõe uma perfeita articulação e sintonia entre os sistemas de ensino regular e de educação profissional. São complicadores que não podem ser perdidos de vista.

Nessa linha de raciocínio, a visão do CNE, centrada na concepção de desenvolvimento humano da UNESCO, ao tentar dar às competências gerais uma perspectiva educacional abrangente e, ao mesmo tempo, articulá-las ao mundo do trabalho, pode desdobrar-se em alguns impasses ao ser trabalhada pelas escolas. Os procedimentos práticos correm o risco de resvalar para a generalidade, arrastando competências e habilidades para o poço de indefinição e inoperância da concepção de preparação para o trabalho da Lei n. 7.044/82.

Em síntese, o que chama a atenção é que as condições reais devem ajustar-se às diretrizes, e não as diretrizes às condições reais. Como é do conhecimento geral, aí não reside nenhuma novidade, o que é desanimador. Outra constatação é que enquanto as borboletas podem voar na mente dos iluminados, a escola deve ser realista e trabalhar nas condições existentes, por mais adversas que elas possam parecer.

De qualquer modo, objetivos claros não se delineiam a partir de diretrizes obscuras ou muito complexas para o cotidiano da escola pública. A ampliação do "repertório de verdades pedagógicas", num horizonte de consenso decretado, pode artificializar algo que, pelo próprio discurso oficial, é de natureza flexível, dinâmica e, até mesmo, imprevisível.

Porém, a assunção de diretrizes impenetráveis e o cumprimento de um ritual litúrgico

10. O CNE inspira-se, expressamente, nas concepções da UNESCO constantes da publicação "Educação, um tesouro a descobrir". A UNESCO indica os pilares do conhecimento, definidos em função de quatro aprendizagens fundamentais que, em última instância, podem ser resumidas em duas: aprender a aprender e aprender a ser (Delors, 1998, p.89-90). Uma das dimensões do aprender a ser seria a competência pessoal, "que se apresenta como uma espécie de coquetel individual, combinando a qualificação, em sentido estrito, adquirida pela formação técnica e profissional, o comportamento social, a aptidão para o trabalho em equipe, a capacidade de iniciativa, o gosto pelo risco" (idem, p.94). 
para sua discussão e adoção é a trilha mais percorrida pelos fazedores de política. Se é o caminho certo para a educação brasileira, a História dirá.

\section{OS MEANDROS DO RITUAL LITÚRGICO}

Há uma reflexão de Thurow (1997) sobre as implicações da "sociedade do conhecimento" no processo de tomada de decisões que traz alguma luz sobre as práticas atuais da intelligentzia no que diz respeito à elaboração de políticas e propostas educacionais. Alguns podem afirmar que se trata de uma atitude normal das tecnocracias - tendentes a encastelar-se - de usar o saber como poder e serem refratárias ao diálogo. Todavia, parece que "razões de Estado", "confidencialidades" e agendas pautadas em categorias consensuais afinadas a tendências mundiais podem ter outras explicações.

Uma questão que se coloca de plano no cenário do debate educacional brasileiro diz respeito ao perfil controvertido apresentado pela intelligentzia ao participar do poder e desempenhar papéis que envolvem decisão e direção. Chomsky, em entrevista a Linhares e Garcia (1996, p. 38-9), resolve a charada com uma resposta simples e direta. Argumenta que, desde os tempos bíblicos, o intelectual sempre teve duas opções: subordinar-se ao poder como porta-voz do interesse dos poderosos e obter prestígio, privilégio e riqueza ou ligar-se ao povo, assumindo, nesse caso, o ônus decorrente. Todavia, essa opção bipolar e seus desdobramentos, no dúbio contexto político atual, não são assim tão cristalinos.

É provável que a experiência política historicamente propiciada aos intelectuais tenha sido insuficiente para o exercício de suas idéias democráticas e promova uma espécie de "crise de identidade na medida em que têm a oportunidade de associar-se ao poder. Tal aproximação parece assemelhá-los à tecnocracia preexistente e aprisioná-los às teias da gramática da política. Nessa perspectiva, concepções repisadas de democracia social e participativa, sempre presentes no discurso, tendem a empalidecer ou recompor-se ao sabor das práticas estratégicas de compromisso, conciliação e consenso.

O universo cultural e simbólico nacional e as relações tradicionais de poder infiltramse na definição das políticas educativas e impregnam seus processos de formulação, seus conteúdos, sua concretização e resultados. Nesse contexto, o distanciamento verbal de concepções e relações autoritárias não impede que padrões herdados, historicamente engendrados e profundamente incorporados ao pensar e ao fazer político e social sejam apropriados e explorados no decorrer desses processos.

Em tal quadro de referências, a intelligentzia incorpora, como o Príncipe de Maquiavel (1993), o poder de captar, organizar e expressar os desejos dos destinatários da política, bem como iluminar, arbitrar, guiar e racionalizar a ação dos executores. A força desse poder emana da legitimidade garantida pela manipulação de algumas categorias-chave, como representação (política), estratégia e competência (autoridade intelectual).

A indefinição que acompanha a idéia de representação política, devido à persistência 
de relações autoritárias e aos atuais questionamentos que sofre, "em virtude das profundas transformações na natureza do que deve ser representado na esfera do político" (Garretón, 1997, p. 135), favorece esse estado de coisas. É recorrente o argumento de que, uma vez eleito, o governo fala, decide e faz em nome do povo. Reclamos generalizados (que incluem secretários de Estado, conselheiros, associações docentes e intelectuais)" não sensibilizam dirigentes e legisladores a partilhar decisões.

Como desdobramento, a neutralização da divergência - dimensionada negativamente - é promovida por estratégias adotadas quando a cooperação se faz necessária. $\bigcirc$ pressuposto de que há uma contraposição e, ao mesmo tempo, uma hierarquia entre consenso e conflito marca as regras do jogo do debate público de iniciativa oficial, configurado como teatro de legitimação. Mesmo que a mobilização permaneça como palavra de ordem, o dissenso deve ser cuidadosamente administrado e considerado aceitável apenas em relação ao acidental.

Tais estratégias - eleitas sob a égide do poder - enquadram-se no que Certeau (1994, p. 99) define como "cálculo (ou manipulação) das relações de força que se torna possível a partir do momento em que um sujeito de querer e poder (uma empresa, um exército, uma cidade, uma instituição científica) pode ser isolado". Esse isolamento constrói um locus de visão e controle espaço-temporal a partir do qual é articulada a credibilidade do consenso nacional.

O saber é peça-chave num jogo que supervaloriza a competência da expertise nacional e internacional e desqualifica o pensamento divergente, pela simples razão da divergência. É um saber que dispensa argumentos, um abuso do saber. Conforme assinala Certeau (1994, p.67), "não podendo ater-se ao saber, o perito se pronuncia em nome do lugar que sua especialidade Ihe valeu”. Tal panorama facilita aos fazedores de política a garantia de compromissos firmados e a coerência de planos e reformas a agendas a priori acordadas.

Essa problemática tem, ainda, outra face. Azevedo (1997) ressalta que a tradição autoritária e conservadora brasileira constrói representações sociais de subordinação e consentimento em todos os espaços, propiciando a avalização da participação regulada e da cidadania outorgada. Nessa ótica, o outro é reconhecido em sua inferioridade e não em sua alteridade. Isto é, se todos são "o grande público", esse público não é, necessariamente, "respeitável".

Assim, há redução de espaços legítimos de participação e negociação para os

\footnotetext{
I I São notáveis as manifestações de Secretarias da Educação em relação a políticas e programas do governo federa (Weber, 1998, Athias, 1998) e as críticas ao autoritarismo da administração educacional paulista (Athias, Campos, 1998, Trevisan, 1998, Rossetti, 1998). Como contraponto, também é exemplar a defesa feita pela conselheira Guiomar Namo de Mello: "As críticas de falta de diálogo não procedem porque o fórum mais legítimo, o Congresso Nacional, discutiu essas mudanças por mais de dez anos". A conselheira refere-se à tramitação da nova LDB, realizada sob o mesmo corolário...
} 
"subalternos" e dificuldades para o enraizamento de mecanismos de representação de seus reais interesses. Em decorrência, "os processos pelos quais as políticas públicas são definidas e implementadas, quase sempre, têm-se dado sem que se considerem os espaços de representação da maioria da população" (Azevedo, 1997, p. 113). Desse modo, a construção de uma política educativa "passa a ser uma atividade especializada, perdendo seu caráter convocatório para se tornar instrumental e de cúpula” (Garretón, 1997, p. 136).

As regras do jogo do debate público incluem, também, o controle da informação. A manipulação seletiva torna-se critério básico para a escolha de o que divulgar, quando divulgar, como divulgar e para quem divulgar ${ }^{22}$. A desinformação assume várias faces: o alheamento assumido ou provocado, a incompetência dos mal-informados e tendenciosos e a ignorância pura e simples dos fatos em decorrência da falta de transparência e enclausuramento dos "órgãos técnicos", em nome do bom andamento dos estudos e ações.

Ribeiro (1997) assinala que "a modernidade, na medida em que é revolucionária, procura suprimir a separação entre o palco e a platéia. Na medida em que é reformista, tenta reduzir essa distância. E quando é conservadora, aposta no aumento e sacralização desse abismo". Em sua opinião, os reformistas podem até ampliar o espaço de participação popular mas não alimentam ilusões quanto ao seu alcance. Já os conservadores reduzem a política à publicidade: a teatralidade garante o sucesso da estratégia. O processo reformista brasileiro na área educacional parece ter escolhido a terceira opção...

Nesse quadro, instala-se um ritual manipulador que simula a participação democrática por intermédio de um conjunto articulado de procedimentos: seleção de sujeitos com direito à palavra e à credibilidade, definição de direitos e deveres para os "convocados", criação de expectativas sempre positivas, instauração da confiança do destinatário a qualquer custo.

Os interlocutores competentes são aqueles capazes de interpretar corretamente as expectativas do poder e garantir sua credibilidade e legitimação perante a opinião pública. Como no teatro grego, constituem o "coro", isto é, personificam o povo junto aos dirigentes e sustentam, junto ao público em geral, "o interesse cênico" (Landowski, 1992, p. 25).

Incompetentes e/ou retrógrados são os que se atrevem a emitir um pensamento divergente. Os "eleitos" personificam o apoio, o consenso, a opinião, a legitimação. Nem sempre participam da decisão, limitada a esferas restritas, encarregadas de "compatibilizações". Respostas não adequadas sempre podem ser reinterpretadas, reavaliadas e desqualificadas.

Porém, ninguém é capaz de tudo saber e a tudo responder. A construção de políticas deve entrelaçar-se à prática criada nas escolas. Sem amarração com o vivido o debate

12. Os interlocutores da audiência pública sobre as Diretrizes Curriculares para o Ensino Médio, realizada em São Paulo no dia 18/5/98, selecionados segundo critérios duvidosos de representatividade, receberam o documento com apenas 48 horas de antecedência. 
teórico flutua no ar e não se expressa no cotidiano, reduzindo-se a bricolagens, a caleidoscópicas maneiras de fazer dos atores, que traduzem "inúmeras e infinitesimais metamorfoses da lei, segundo seus interesses próprios e suas próprias regras" (Certeau, 1994, p. 40).

O pensamento divergente, em contraposição à estratégia governamental que o exclui do processo decisório, pode adotar a tática de mobilização, isto é, uma "ação calculada que é determinada pela ausência de um próprio" (espacial e temporal) que lhe permite agir "dentro do campo de visão do inimigo e no espaço por ele controlado" (Certeau, 1994, p. 100). Ao lidar com a ausência de poder, o terreno imposto o limita à formulação de réplicas, como é o caso da proposta alternativa do Plano Nacional de Educação - PNE -, depositada no Congresso Nacional. Todavia, a visão distorcida de tempos e espaços dificulta a articulação de novas realidades.

A força da tática, porém, segundo Certeau (1994), está na habilidade de explorar e apropriar-se de tempos e oportunidades. As contradições da participação controlada e da autonomia decretada fazem com que escapem do controle total e embutem condições de possibilidade e brechas para novas formas de participação e construção da autonomia.

$\bigcirc$ que alicerça a segurança do poder? A fé na própria capacidade de apreender a realidade, de articular propostas coerentes, de convencer os reais executores a seguirem caminhos que não escolheram nem desenharam? Ou o respaldo do saber consensual exógeno?

No primeiro caso, há um toque de onipotência. No segundo, tal sustentação implica a confiança incondicional na força dos espelhos, na prospecção tecnicista, na expressão qualitativa da estatística, nos poderes mágicos da tecnologia, na chave do sucesso incorporada à subordinação da educação ao mercado e à submissão do conhecimento à tecnologia, na ação disciplinadora da avaliação externa, na cornucópia financeira das parcerias e no poder da autonomia decretada em construir novas realidades educacionais.

É provável que tais crenças justifiquem o direito de interferir na "realidade rebelde", impor-lhe condições e soluções e controlá-la, de bloquear iniciativas não consensuais, de induzir a escola à cegueira seletiva. Não haveria, nesse caso, o perigo de promover um "escolaricídio"? Com certeza, não é essa a intenção dos gestores da educação brasileira...

\section{REFERÊNCIAS BIBLIOGRÁFICAS}

ATHIAS, G. Estados desconhecem metas de FHC para ensino. O Estado de S. Paulo, 5 set. 1998, p. A-9.

ATHIAS, G., CAMPOS, I.W. Covas fará parcerias com setor privado. O Estado de S. Paulo, I nov. 1998, p. A- 14.

AZEVEDO, J.M.L. As Relações sociais no Brasil, a política educacional e os desafios para 
uma educação de qualidade. Revista Brasileira de Política e Administração da Educação, v. 13, n. I, p. 107-16, 1997.

BANCO INTERAMERICANO DE DESENVOLVIMENTO. Brasil: programa de reforma de educación profesional (BR-0247); operación no. 1.052/OC-BR, 5 nov. 1997.

Projeto BR-247: expansão e melhoria da qualidade de ensino de $2^{\circ}$ grau; Ficha Ambiental, 25 jun. 1995

Projeto BR-247: professional education sector reform Brazil education loan; Approval tentatively scheduled for October 15, 1997 a.

Projeto BR-247: reforma del sector de educación profesional; Ficha Ambiental revisada, 3 set. 1996.

Projeto BR-247: reforma del sector de educación profesional; Informe Ambiental; actualización, 14 fev. $1997 b$.

Projeto BR-247: reforma do setor de educação profissional (PROEP); environmental and social impact report (ESIR), 12 set. 1997c.

BANCO MUNDIAL. Educación técnica y formación profesional. Washington D.C.: Banco Mundial, 1992.

Issues in Brazilian secondary education. Washington D.C: Latin American and Caribbean Regional Office, 1989.

Prioridades y Estrategias para la Educación (Examen del Banco Mundial). Washington D.C.: Banco Mundial, 1996.

BIRDSALL, N., SABOT, R.H. (ed.) Opportunity foregone: education in Brazil. Washington D.C.: IADB, 1996.

BRASIL. Leis, Decretos, etc. Decreto n.2.208 de 17 abr. 1997. Regulamenta o $2^{\circ}$ do art. 36 e os artigos 39 a 42 da Lei n.9.394/96. Diário Oficial da União, Braśília, I 8 abr. 1997.

Emenda Constitucional n. 14 de 12 set. 1996. Modifica os art. 34, 208, 21 I e 212 da Constituição Federal, e dá nova redação ao art. 60 do Ato das Disposições Constitucionais Transitórias. Diário Oficial da União, Brasília, 13 set. 1996.

Lei n. 9.394 de 20 dez. 1996. Estabelece as Diretrizes e Bases da Educação Nacional. Diário Oficial da União, Brasília, n. 248, 23 dez. 1996a, p. 27.833-84I.

Ministério da Educação e Cultura. Conselho Nacional de Educação. CEB. Âmbito e significado das diretrizes curriculares nacionais para o ensino médio deliberadas pelo Conselho Nacional de Educação. Relatora: Guiomar Namo de Mello. Versão preliminar em discussão, 18 fev. 1988. (cópia impressa) 
CEB. Diretrizes nacionais para a organização curricular do ensino médio. Relatora: Guiomar Namo de Mello. Versão em discussão, maio de 1998. (cópia impressa)

CEB. Parecer n. 15/98: Diretrizes Curriculares Nacionais para o Ensino Médio. Relatora: Guiomar Namo de Mello. I jun. 1998a. FTP: http://www.mec. gov/cne.

CEB. Resolução n. 3, 26 jun. 1998. Institui as diretrizes curriculares nacionais para o ensino médio. Diário Oficial da União, Brasília, 6 ag. 1998b.

Planejamento político-estratégico: 1995/1998. Brasília: MEC, 1995.

PROEP: Programa de expansão da educação profissional. Online: http:// www.mec.gov.br. s.d.

Democratização das escolas da rede federal de educação tecnológica. Brasília: 1995a.

Política para a educação tecnológica. Brasilia: 1995b

SEMTEC. Política para o ensino médio. Brasília: 1995c.

Proposta de regulamentação da base curricular nacional e de organização do ensino médio. Brasilia: 1997a.

Reforma do ensino técnico. Brasília: MEC; MTB, 1996c.

Secretaria do Planejamento. IPEA. Relatório sobre o desenvolvimento humano no Brasil: 1996. Internet: http: //www.undp.org.br/rdhbl.htm, 9.7.1999.

CARDOSO, F.H. Mãos à obra, Brasil: proposta de governo. Brasília, 1994.

CARROLL, L. Alice no país do espelho. 3a.ed. São Paulo: Brasiliense, 1961.

CASTRO, C.M. O secundário: esquecido em um desvão do ensino?, Brasília: MEC/INEP, abr. 1997. (textos para discussão, 2).

CASTRO, C.M., CARNOY, M. Como anda a reforma da educação na América Latina? Rio de Janeiro: FGV/BID, 1997.

CERTEAU, M. de. A Invenção do cotidiano: artes de fazer. 2.ed. Petrópolis: Vozes, 1994.

CROUCH, L. A Secondary education expansion: future problems and prospects (prepared under consultancy to the World Bank), 1995. (Seminario Internacional "La Educación Secundaria en Europa y América Latina: Reformas y Perspectivas de Futuro. CuencaEspaña).

CUNHA, L.A.C. Ensino médio e ensino profissional: da fusão à exclusão. Caxambu, 1997. (Reunião Anual da Anped, 20)

DECLARAÇÃO de Nova Delhi. Em Aberto, Brasília, n. 59, 1993. 
DELORS, J. (coord.) Educação: um tesouro a descobrir. São Paulo: Cortez; Brasília DF: MEC/NNESCO, 1998.

FERREIRA, A.B. de H. Novo Dicionário da Língua Portuguesa, I a ed., I $5^{a}$ impressão, Rio de Janeiro: Nova Fronteira, s/d, p. 479.

FERRETTI, C.J. Formação profissional e reforma do ensino técnico no Brasil: anos 90. Educação \& Sociedade, n. 59, p. 225: 69, 1997.

GARRETÓN, M.A. Pontos fortes e fracos dos novos consensos sobre educação. Cadernos de Pesquisa, n. I01, p. I28- 40, jul. 1997.

HORTA, J. S. B. As Diferentes concepções de "diretrizes e bases" e a questão do nacional na história da educação brasileira. Cadernos ANPEd n. 2, p. 5-13, 1989.

LANDOWSKI, E. A Sociedade refletida. São Paulo: EDUC; Pontes, 1992.

LINHARES, C.F., GARCIA, R.L. (orgs.). Dilemas de um final de século: o que pensam os intelectuais. São Paulo: Cortez, 1996.

LONDOÑO, J. L. Pobreza, desigualdad y formación del capital humano en América Latina 1950-2025. Washington D.C.: World Bank, 1996.

MAQUIAVEL, N. O príncipe. São Paulo: Abril Cultural, 1993, v. 9, p. 7- 120 (Os Pensadores).

MELLO, G.N. Cidadania e competitividade: desafios educacionais do terceiro milênio. São Paulo: Cortez, 1993.

A Reforma do ensino primário e secundário na Inglaterra. São Paulo: TD/IESP, 14 jan. 1994.

MERQUIOR, J.G. O véu e a máscara: ensaios sobre cultura e ideologia. São Paulo: T.A. Queiroz, 1997.

OLIVEIRA, J.B.A. Repensando o ensino de $2^{\circ}$ grau: subsídios para a discussão. Ensaio, v.3, n.8, p.285-3/2, 1995.

PNUD/IPEA. Relatório sobre o desenvolvimento humano no Brasil - 1996. http: // www.undp.org.br/rdhbl.htm, 9/7/99.

RIBEIRO, R.J. Feitiçarias do capital. Folha de S. Paulo, 17 ago. 1997.

ROSSETTI, F. Notícias do projeto aprendiz. Folha de S. Paulo, 20 nov. 1998.

THUROW, L.C. O Futuro do capitalismo. Rio de Janeiro: Rocco, 1997.

TREVISAN, L. Fim da repetência é alvo de debate. O Estado de S. Paulo, o nov. 1998, p. A- 14 .

WEBER, S. Novos padrões de financiamento e impactos na democratização do ensino. Cadernos de Pesquisa, n. 103, p.5-13, mar. 1998. 